\title{
The Ex-Post Economic Evaluation of Water Resource Management in South Korea: Meta-Regression Analysis
}

\author{
Hyun No Kim ${ }^{1}$ and SoEun Ahn ${ }^{1, *}$
}

1 Department of Sustainable Development Research, Korea Environment Institute, 30147

Sejong, Korea; hnkim@kei.re.kr

* Correspondence: seahn@kei.re.kr

Abstract: Water management can improve the quality of valuable ecosystem services but can be costly to implement and the management costs are covered by national taxes collected by water users. Based on 30 valuation studies of water quality improvement from the Environmental Valuation Information System (EVIS) database provided by Korea Environment Institute (KEI), a meta-regression analysis was employed to measure the benefits that major river basins provided to the society. We compare these benefits to the costs, namely River Management Funds (RMFs) which are financial resources to support a variety of projects for managing and improving upstream water quality. Based on benefit-cost comparison, this study evaluates the efficiency of water resource management in South Korea. This study also provides policy options that are helpful to maintain the sustainability of water resource by improving the planning and performance of water management in the long run.

Keywords: Economic evaluation, Water resource management, Meta-regression analysis, River management funds, Sustainability of water resources 
1. Introduction

Water management can improve the quality of valuable ecosystem services. The implementation of the water management can, for instance, result in stabilization of water quality. In other words, the water management can have a significant impact on water environment and this can lead to changing the amount and quality of the services that the aquatic ecosystem provides [1]. Therefore, water management can provide tangible/intangible benefits as a consequence of the increased water quality to the society. On the other hand, the implementation of water management can be costly and the associated costs are covered by national taxes collected by water users.

The ex-post evaluation of the government policy has recently received attention since it is helpful to identify whether the government is making a sound investment in terms of their expenditure, which can be in turn useful to determine the accomplishment of its goal. A wide range of approaches can be applied for the policy evaluation but the benefit-cost analysis has been widely adopted to measure the magnitude of the policy impact measured in economic aspects. The importance of benefit-cost comparison for the water management has been also emphasized by the Water Framework Directive in the European Union. Accordingly, it is worthwhile to conduct the ex-post evaluation of the government policy to determine the effectiveness of the policy, which can provide a valuable guideline to maintain the sustainability of water resources by improving the planning and performance of water management in the long run.

In South Korea, there are four major river basins, e.g., belonging to the Han River, the Geum River, the Nakdong River, and the Yeongsan-Seomjin River. These four major rivers 
are an important water resource to provide many tangible and intangible beneficial services to the stakeholders. To be more specific, they are used as a primary source for drinking water, recreational activities, aesthetic amenities, and economic development.

Increasing recognition of the importance of water management in these four river bodies has led the National Assembly which is the Korea's central legislature to enact the Han River Act in February 1999 in an attempt to ensure more systematic efforts for improving water quality. This law proposed collecting water use charges as an additional way of raising the necessary financial resources to improve water quality in the river. The other three major river systems soon followed the suit and adopted water use charges of their own. The water use charges collected became the seed money for the River Management Funds (RMFs) in August 1999 for the Han River and in 2002 for the other three major rivers.

Water use charges, based upon the Beneficiary Pays Principle (BPP), were introduced to offset the losses in opportunity costs associated with regulation against various economic activities in upstream regions along the river basin. Since the Han-River Act enacted in 1999, midstream and downstream water users have paid water use charges to provide financial resources for resident support projects in upstream communities and to support the project costs required to stabilize the water quantity and quality in the upstream regions of the river basins. However, there have been many controversies and disputes among stakeholders with respect to the efficiency of RMFs management. Nevertheless, few systematic efforts 
have been made to solve these on-going issues ${ }^{1}$. This motivates us to suggest practical solutions by performing the economic analysis that explores plausible evaluation of the effectiveness of water resource management.

Consequently, this study aims to provide more convincing evidence with respect to the assessment of benefits provided by the major river basins and to compare these benefits to costs, applying a meta-regression analysis which can bring all relevant study results and information together that have been gathered on all stakeholders [2]. Although a meta-regression analysis has been mainly used as a method for transferring the benefit from the existing cases to new cases, this method is also applicable for the assessment of benefits provided by environmental goods and services [3]. The number of case studies using a meta-regression analysis has been conducted in many countries ([4-10] among many others) but to the best of our knowledge, this study may be the first attempt to apply meta-analysis to evaluate the economic efficiency of water resource management in South Korea based on benefit-cost analysis.

We specified a meta-regression model which allows for estimating different benefits provided by each river and compared them to its own RMFs (costs). The methods utilized in this study represent an effective approach for an ex post analysis of natural resource policy/regulation/program etc., which would be helpful for those who are interested in conducting a similar study.

\footnotetext{
${ }^{1}$ Exception includes Shin et al. [2] which applied benefit transfer approaches to determine efficient allocation of the benefits provided by the Han River between the stakeholders.
} 
This paper is organized as follows. The next section describes the methodology that includes description of water management, method, empirical specification of meta-regression analysis, and data. The empirical results are then presented including a section that outlines benefit-cost analysis. This article closes with some policy recommendations.

\section{Water Management in South Korea}

The Han River basin encompasses 28 mid-sized regions, 7 metropolitan cities and provinces including 112 cities, counties, and boroughs; the Geum River basin, 22 mid-sized regions, 8 metropolitan cities and provinces including 47 cities, counties, and boroughs; the Nakdong River basin, 33 mid-sized regions, 9 metropolitan cities and provinces including 87 cities, counties, and boroughs; the Yeongsan-Seomjin River basin, 31 mid-sized regions, 5 metropolitan cities and provinces including 42 cities, counties, and boroughs. A map showing the course of the four river basins and stakeholders by geographical locations is presented in Figure 1.

The RMFs were introduced in an effort to ensure win-win cooperation among upstream, midstream, and downstream communities as well as users of water resources by effectively managing and mitigating their conflicts of interests. The RMFs espouse the BPP that those who benefit from using water, ought to pay for not only their use but also all the expenses involved in providing the services and benefits they need to them. The overarching objective of the RMFs is thus to raise and manage the financial resources necessary to ensure appropriate management of water resources and pollutants through 
effective water management projects and resident support projects for upstream communities by funding these projects with money collected from mid and downstream users.

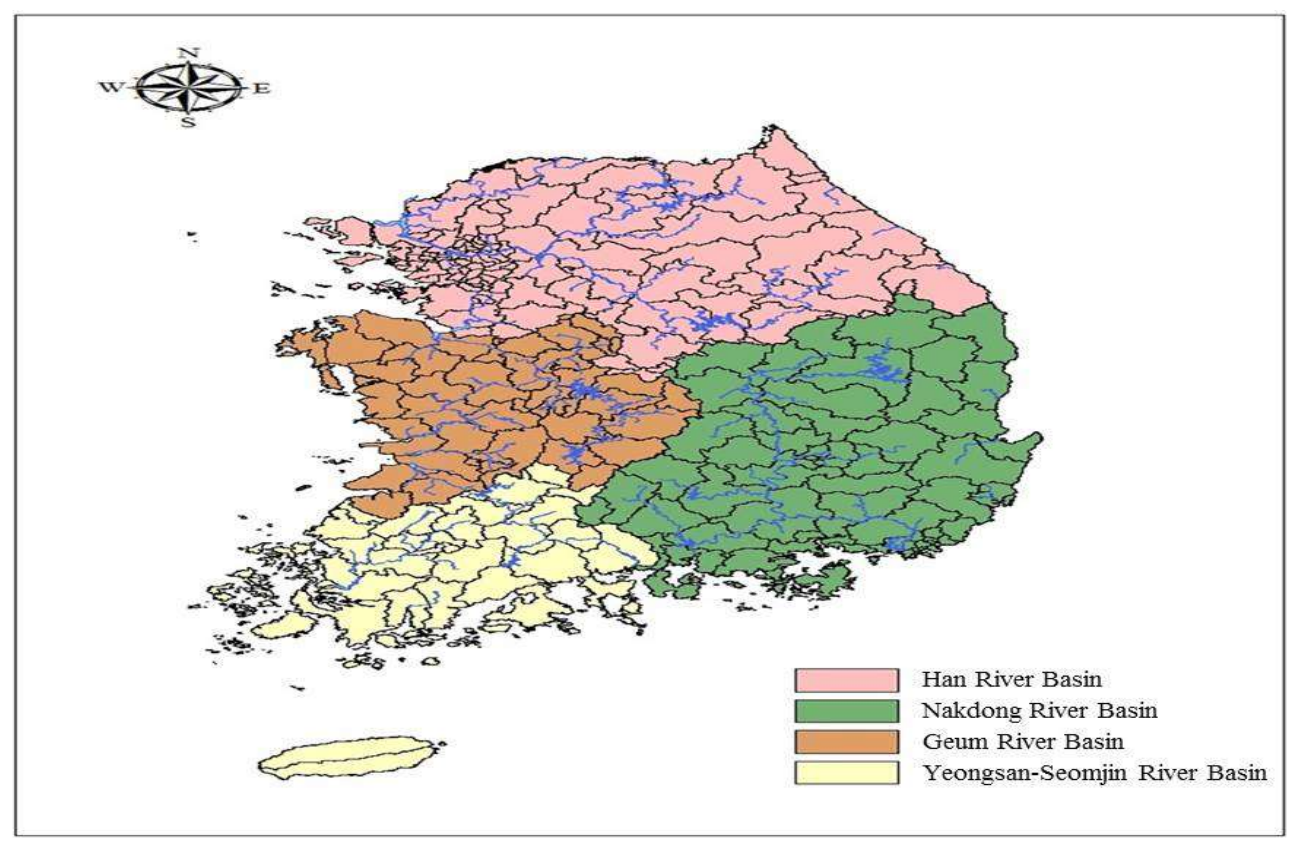

Figure 1. The Four Major River Basins in South Korea.

The RMFs are mostly made up of water use charges collected from midstream and downstream communities. The water use charges have been rising steadily due to increase in project funds supported by RMFs, increase in water consumption, and increase in the number of populations who pays water use charges year in and year out. In 2016, the water use charge rates were KRW 170 per ton for the Han, Nakdong, and Geum Rivers, and KRW 160 per ton for the Yeongsan-Seomjing River.

As briefly explained earlier, the water use charges have been introduced to compensate upstream communities for the restrictions on their economic activities that are necessary to provide clean water for midstream and downstream communities. The charges are levied from midstream and downstream communities and channeled to upstream ones. Based on 
water use charges and returns on their investment, the RMFs raised a total of KRW 10.1436 trillion in fund by 2015. The Han River basin contributed 57.1\%; the Nakdong River basin 24.1\%; the Geum river basin, 10.5\%; and the Yeongsan-Seomjin River basin, $8.3 \%$.

The RMFs support a variety of projects for managing and improving upstream water quality. There are mainly five types of such projects, i.e., resident support projects, environmental treatment infrastructure projects, water quality improvement projects, land purchase and riparian zone projects, and the total pollutant management projects. Together, the RMFs expended KRW 10.0519 trillion on such projects as of $2015.47 .7 \%$ of total expenses went to environmental treatment infrastructure projects; $18.7 \%$ to resident support projects; $18.3 \%$ to riparian zone projects; $8.3 \%$ to water quality improvement projects; $5.4 \%$ to total pollutant management projects; and $1.6 \%$ to administrative expenses.

\section{Methodology}

\subsection{Benefit Transfer and meta-regression analysis}

The economic benefits of water resources or water management policy can be evaluated via original research using non-market valuation methods such as contingent valuation method (CVM), hedonic property methods, choice experiment, etc. [11-13]. However, conducting the original research is non-trivial because of constraints on time and budgets [3]. In such cases, benefit transfer which uses existing data or information from previous research has been alternatively applied.

A benefit transfer approach was formally developed in the early 1990's in response to an increased need for the valuation of environmental resources when it is difficult to 
conduct the original research due to limitations on time, budget, or data availability $[3,9,14,15]$. In other words, this approach has been widely used in the contexts of environmental and resource management, applying research results from pre-existing studies to predict benefits or other economic information for a new context $[16,17]$. In general, two types of benefit transfer- value transfer and function transfer can be applied where the former applies the summary statistics from the previous studies while the latter applies statistical methods to examine relationships between value estimates and characteristics of the study sites. Compared to value transfer, the function transfer is more flexible in terms of its ability to adjust the different attributes between the existing and new studies. Since the Water Framework Directive in the European Union has recognized the importance of benefit-cost comparison for the river basin management, the literature has increasingly utilized function transfer approaches [2,4-7,19-23].

Meta-regression analysis (MRA), one of the function transfer approaches, attempts to estimate the impact of quantifiable factors on outcome variables via regression analysis. In other words, the dependent variable in MRA is represented by a summary statistic measured as consumer surplus (CS) or willingness to pay (WTP) obtained from each individual study. The explanatory variables include factors which may have an influence on outcome variables (i.e. dependent variable). The MRA is more attractive than other approaches since it is possible to extract the apparent influences of particular factor such as the estimation methods applied, the study design, and data characteristics on the research outcomes. In addition, the MRA is able to statistically identify differences in individual study results due to the differences in summarized statistics. As discussed by Shrestha and Loomis [10] the 
MRA is appealing based on the following aspects. First, it can provide more robust measures of central tendency susceptible to the intrinsic distribution of study values. Second, the alternative methodology can be utilized when forecasting the values from the meta-regression model. Third, the differences between the actual study site and the new policy site can be controlled for by adjusting the level of explanatory variables peculiar to the new site.

Data for the MRA has a similar structure to panel data format since each study can have several different value estimates based on different scenarios. Put differently, if a number of observations extracted by individual studies are different (e.g., number of outcome values), it is similar to unbalanced panel structure. The panel data can be in general controlled for by employing either a fixed effect model (FEM) or a random effect model (REM). Assuming variation shared by observations in the same study to reflect their structural differences, the FEM includes dummy variables for each individual study. By doing so, however, the FEM is deprived of the degrees of freedom in accordance with a number of individual studies. On the other hand, individual studies in the REM are regarded to be randomly sampled from a mother distribution of observations [15]. That is, it can be assumed that variation between observations in the same study could be a stochastic variable in the REM. The REM is composed of two error terms-one related to individual observations and the other related to specific studies. Compared to FEM, REM would not cause problems such as loss in the degrees of freedom. 


\subsection{Model specification}

The selection of the appropriate model between FEM and REM can be performed based on a Hausman test where the null hypothesis is that the preferred model is REM which is based on generalized least squares estimation and the alternative one is FEM which is estimated by ordinary least squares (OLS). The test results indicate that the null hypothesis cannot be rejected implying the REM is preferred to $\operatorname{FEM}\left(\chi^{2}(5)=5.75, p\right.$-value $\left.=0.332\right)$ ). Given the selection of REM, we then conducted Breusch and Pagan Lagrangian Multiplier (LM) test for the presence of random effects (i.e., the presence of variation between observations in the same study). The null hypothesis of this LM test is that variances across individual studies are zero while they are not in the alternative hypothesis. If the null hypothesis is rejected, the REM is statistically better than a classical OLS regression model. As a result of LM test, the null hypothesis is not rejected supporting no presence of random effects $\left(\chi^{2}(1)=0.80, p\right.$-value $\left.\left.=0.186\right)\right)$. Based on these statistical tests for the panel data structure, we estimated the following meta-regression model.

$$
\operatorname{lnwtp}_{i}=\alpha+\beta x_{i}+\sum_{j} \gamma_{j \times \text { improve }} j \times \text { improve }_{i}+\varepsilon_{i}
$$

where $\operatorname{lnwtp} p_{i}$ is the log transformation of willingness to pay from the study $i$ (in this case, willingness to pay per month per household), $x_{i}$ is a vector of independent variables including characteristics of study $i$ and socio-economic variables. $j \times$ improve $_{i}$ represents interaction variables between $j$ ( $\mathrm{j}=$ han, geum, and nakdong) where $j$ is a dummy variable for each river basin and improve which donates the level of water quality improvement. $\alpha$ is constant and $\beta$ are the vector of parameters to be estimated. $\gamma_{j \times i m p r o v e}$ are the parameters 
to be estimated capturing the impact of water quality improvement differentiated by each river on the dependent variable. $\varepsilon_{i}$ represents an error related to individual observations with mean zero and variance $\sigma_{\varepsilon}^{2}$.

Based on the parameter specified in Equation (1), the economic impact for a marginal change (i.e. marginal wiliness to pay, MWTP) associated with increase in water quality can be derived as follows.

$$
M W T P_{j}=\gamma_{j \times \text { improve }} \times W T P_{j}^{\text {mean,median }}
$$

where in Equation (2) $\mathrm{j}=$ han, geum, and nakdong and $W T P_{j}^{\text {mean,median }}$ is the mean and median WTP values related to each river basin in the sample, respectively.

Following Shrestha and Loomis [10], we performed some statistical tests to evaluate the validity of our meta-regression model. First, we compared predicted WTP values to the original WTP values and verified whether these two values are statistically the same using paired $t$-tests. The null and alternative hypothesis for this test is specified as follows.

$$
H_{0}: W T P_{i}^{p v}-W T P_{i}^{o v}=0 H_{1}: W T P_{i}^{p v}-W T P_{i}^{o v} \neq 0
$$

where in Equation (3) $W T P_{i}^{p v}$ is the predicted WTP values from meta-regression model for $i$ observation and $W T P_{i}^{o v}$ is the original WTP values from the original studies.

Whether to accept $H_{0}$ or not will be determined by the statistical significance of a paired $t$-test. The null hypothesis will be accepted if a paired $t$-test is statistically significant implying two WTP values appear to be convergent, which demonstrates the credibility of our meta-regression model for other applications. The testable hypotheses used in this study can be re-expressed in Equation (4) 


$$
H_{0}: \mu_{D}=0 \quad H_{1}: \mu_{D} \neq 0
$$

where $\mu_{D}$ is the mean of the difference between $W T P_{i}^{p v}$ and $W T P_{i}^{o v}$.

The t-statistic used for hypothesis testing in Equation (4) is calculated as follows.

$$
t=\frac{\left(\bar{D}-\mu_{D}\right)}{S_{D} / \sqrt{n_{p}-1}} \text { with d.f. }=n_{p}-1
$$

where in Equation (5) $D$ is the difference between each pair of $W T P^{p v}$ and $W T P^{o v}, \bar{D}$ is the mean of the sample difference scores, $n_{p}$ is the number of matched pairs of scores in the sample, and $S_{D}$ is the sample standard deviation of the difference scores. The validity of predicted values from the meta-regression model will be supported if the null hypothesis in Equation (4) is not rejected (i.e., $t$-value is statistically insignificant).

Second, we also conducted correlation analysis to test the statistical significance of the relationship between predicted WTP values and original WTP values, which can be regarded as another way to assess their statistical similarity [10]. The correlation coefficient analysis we employed is based on Pearson's correlation coefficient which provides the relationship in terms of direction and degree of correlation between these two values. For this analysis, the following hypothesis testing is formulated.

$$
H_{0}: \gamma=0 H_{1}: \gamma \neq 0
$$

where $\gamma$ represents Pearson's correlation coefficient between $W T P^{p v}$ and $W T P^{o v}$. If $H_{0}$ is rejected it means that statistically significant relationship between $W T P^{p v}$ and $W T P^{o v}$ exists, which similar to a paired $t$-test case advocates reliability of a meta-regression model for benefit transfer. With respect to the direction of two values the positive (negative) $\gamma$ indicates as the original studies produce high (low) WTP values, high (low) predicted WTP values are estimated by the meta-regression model. 


\subsection{Data}

The data used for this study are obtained from the Environmental Valuation Information System (EVIS) provided by Korea Environment Institute (KEI). The EVIS establishes the database associated with environmental valuation studies conducted in South Korea and to form the relevant studies we focused on the previous studies which measured the WTPs with respect to water quality improvement in South Korea. As mentioned earlier, since the four major rivers in Korea have provided stakeholders with various benefits such as a primary source of drinking water, recreational activities, and aesthetic amenities, this study aims to estimate total use value which consists of direct and indirect use value. Included are, therefore, all eligible studies in the meta-regression analysis which estimated economic values for consumptive use and/or non-consumptive use of water resources in South Korea.

Table 1. Definition and relationship between water quality grade and water pollution index.

\begin{tabular}{llllc}
\hline Water Quality Grade & \multicolumn{3}{l}{ Water pollution Indexes } \\
\hline Grade & Definition & BOD & COD & DO \\
\hline 1 & $\begin{array}{l}\text { Very good (most clean water) } \\
\text { drinkable water after simple purification process) }\end{array}$ & Below 1 & Below 1 & Above 7.5 \\
\hline 2 & $\begin{array}{l}\text { Good (clean water in general) } \\
\text { (swimmable; drinkable after general purification process) }\end{array}$ & Below 3 & Below 3 & Above 5 \\
\hline 3 & $\begin{array}{l}\text { Normal (industrial use) } \\
\text { (drinkable after heavy purification process) }\end{array}$ & Below 6 & Below 6 & Above 5 \\
\hline 4 & $\begin{array}{l}\text { Bad (agricultural use) } \\
\text { (no fish; industrial use after heavy purification process) }\end{array}$ & Below 8 & Below 8 & Above 2 \\
\hline 5 & $\begin{array}{l}\text { Very bad } \\
\text { (industrial use after special purification process) }\end{array}$ & Below 10 & Below 10 & Above 2 \\
\hline
\end{tabular}

Source: Water Quality and Aquatic Ecosystem Conservation Act, Ministry of Environment, South Korea. Note: BOD (Biochemical Oxygen Demand), COD (Chemical Oxygen Demand), DO (Dissolved Oxygen). 
We found 51 relevant studies but excluded 21 studies which obviously involved incorrect and/or missing information necessary for the analysis. A final 30 studies which provided 72 WTP estimates in total were used for the MRA. Table 1 provides the relationship between water quality grade and scientific characteristics and the definition of each grade provided by Ministry of Environment, Korea. Using the water quality (WQ) grade in Table 1 most of the studies used in the meta-regression analysis designed the hypothetical scenarios associated with the change in water quality.

We also provide in Table A1 the quantitative information for each study such as study area, valuation technique employed, the level of WQ improvement, baseline WQ grade, economic values evaluated and so on. Of thirty studies, seventeen studies evaluated the WTPs for change in water quality related to Han River basin while the rest (thirteen studies) were associated with Geum or Nakdong River basin (see Table A1). Note that no studies associated with the case of Yeongsan-Seomjin River basin have been found. A majority of studies measured the economic impact for 1 or 2 levels of WQ grade improvement starting with Grade 3. The number of WTP estimates per study ranged from 1 to 9 .

The database in these previous studies included the information such as study area, methodology used, survey mode applied, baseline WQ grade (status quo), sample size collected, and the mean of respondents' characteristics. Table 2 presents the definition of the variables used in our meta-regression model. Following Shrestha and Loomis [10], we first estimated a fully specified meta-regression model including dummy variables for some socio-economic variables such as gender, age, education levels but these variables are finally removed from our optimized model taking their statistical significance and theoretical 
point of view into consideration. The WTP values from all studies were adjusted to constant 2015 Korean currency (KRW) by applying a Consumer Price Index (CPI) provided by Statistics Korea to account for inflationary effects. For independent variables, seventeen variables are included in the optimized meta-regression model of which most of the variables are qualitative dummy variables coded as 0 or 1 , where 1 means the study has its characteristic and 0 otherwise. Based on the income percentiles reported in the data, we created categorical dummy variables for the respondents' income as lowinc through highinc to allow for nonlinear effects of these variables. Similarly, in order to examine relative effects of baseline WQ on WTP values, we generated dummy variables for each WQ grade as good through verybad rather than treating them as continuous variables. Trend variable reflects any systematic changes in WTP values that are not accounted for and is included in order to capture indirect effects of time on WTP values. As explained earlier, we interacted dummy variables for each river basin (han, geum, and nakdong) with the variable for WQ improvement (improve) to capture the economic impact of increase in WQ grade differentiated by each river basin (han $\times$ improve, geum $\times$ improve, and nakdong $\times$ improve).

Table 2. Definitions and descriptive statistics of variables used in the meta-regression model.

\begin{tabular}{lll}
\hline Variable & Description & $\begin{array}{l}\text { Mean } \\
\text { (Std. Dev.) }\end{array}$ \\
\hline WTP & WTP per household per month (2015 KRW) & $\begin{array}{l}4,719.1 \\
(3,392.9)\end{array}$ \\
stypedum & 1 if study was publised in the peer-reviewd journal, 0 otherwise (DV) & $0.778(0.419)$ \\
drinking & 1 if values measured is for drinking water, 0 otherwise (DV) & $0.292(0.4578)$ \\
han & 1 if study area belonged to the Han River basin, 0 otherwise (DV) & $0.583(0.496)$ \\
geum & 1 if study area belonged to the Geum River basin, 0 otherwise (DV) & $0.139(0.348)$ \\
nakdong & 1 if study area belonged to the Nakdong River basin, 0 otherwise (DV) & $0.278(0.451)$ \\
good & 1 if WQ grade is equal to 2 at the time of study, 0 otherwise (DV) & $0.125(0.333)$ \\
normal & 1 if WQ grade is equal to 3 at the time of study, 0 otherwise (DV) & $0.667(0.475)$ \\
\hline
\end{tabular}




\begin{tabular}{|c|c|c|}
\hline bad & 1 if WQ grade is equal to 4 at the time of study, 0 otherwise (DV) & $0.111(0.316)$ \\
\hline verybad & 1 if WQ grade is equal to 5 at the time of study, 0 otherwise (DV) & $0.097(0.298)$ \\
\hline improve & WQ change calculated by hypothetical WQ minus baseline WQ & $1.5(0.504)$ \\
\hline han $\times$ improve & Interaction between han and improve & $0.861(0.827)$ \\
\hline geum $\times$ improve & Interaction between geum and improve & $0.181(0.484)$ \\
\hline nakdong $\times$ improve & Interaction between nakdong and improve & $0.458(0.786)$ \\
\hline$f t f$ & 1 if survey mode was face-to face $(f t f), 0$ otherwise (DV) & $0.903(0.298)$ \\
\hline$c v m$ & 1 if CVM is applied, 0 otherwise (DV) & $0.778(0.419)$ \\
\hline $\operatorname{tax}$ & 1 if payment vehicle is tax, 0 otherwise (DV) & $0.111(0.316)$ \\
\hline truncdum & 1 if truncated model is used, 0 otherwise (DV) & $0.028(0.165)$ \\
\hline lowinc $^{\mathrm{a}}$ & $\begin{array}{l}1 \text { for low income if household's monthly income is } \leq 3,444,000 \\
(2015 \mathrm{KRW}), 0 \text { otherwise (DV) }\end{array}$ & $0.306(0.464)$ \\
\hline midinc ${ }^{\mathrm{b}}$ & $\begin{array}{l}1 \text { for middle income if household's monthly income is }>3,444,000 \\
\text { and } \leq 4,190,000(2015 \mathrm{KRW}), 0 \text { otherwise (DV) }\end{array}$ & $0.292(0.458)$ \\
\hline $\operatorname{highinc}^{\mathrm{c}}$ & $\begin{array}{l}1 \text { for high income if household's monthly income is }>4,190,000 \\
(2015 \mathrm{KRW}), 0 \text { otherwise (DV) }\end{array}$ & $0.403(0.494)$ \\
\hline trend & The study year $(1993=1, \ldots, 2015=23)$ & $14.22(5.04)$ \\
\hline
\end{tabular}

Note: DV denotes dummy variable.

4. Results

\subsection{Meta-Regression Results}

Table 3 shows the results of optimized meta-regression model presented in Equation (1).

As explained earlier, we only include the explanatory variables which are important factors in terms of statistical and/or economic significance to have an influence on WTP values based on meta-analysis literatures in the optimized model. Because of presence of heteroscedasticity robust standard errors are used to obtain unbiased standard errors of OLS coefficients. The mean variance inflation factors (VIF) which quantifies the severity of multicollinearity in an OLS regression were below 5 exhibiting very less collinearity of the estimated coefficients. The meta-regression model does a reasonable job of explaining variation in WTP values $\left(R^{2}=0.78\right)$. 
Except for a few variables, most of the parameters are statistically significant at 5\% level and their signs are consistent with the results of previous meta-regression literature. The estimated coefficient for the dummy variable on stypedum is negative in sign and statistically significant implying the studies published in the peer-reviewed journals produce lower WTP values than other studies. The variable drinking is also negative and significant, indicating the studies measuring the economic values for drinking water quality yield relatively lower estimates of WTP than other studies which estimated total economic values provided by water resources. Compared to other studies, the negative sign of tax variable implies the studies using tax as a payment vehicle have lower WTP values. This is probably due to the fact that respondents exhibited passive payment due to the resistance to pay more taxes. In terms of baseline WQ variables, bad variable is statistically significant with the positive sign only. The coefficient for this variable can be interpreted in comparison to the reference category variable while controlling for the other independent variables. For instance, holding other features constant the studies starting with the $4^{\text {th }}$ WQ grade produce higher WTP values compared to the studies associated with $2^{\text {nd }}$ WQ grade.

The coefficients on the variables, medinc and highinc can be interpreted in a similar way that is applied to baseline WQ case. The magnitude of the medinc coefficient, however, is bigger than that of highinc coefficient implying middle income households have higher WTP values than high income households, which is not of expected result. This deserves some discussion in more detail. This result probably arises from the fact that high income households are less sensitive to the change in water quality conditions than middle income households. For example, if the water quality is improved, middle income households can 
reduce the costs to purify the water for drinking as well as moving costs to enjoy recreational activities in other areas. On the other hand, the high income households can be less affected by the change in water quality conditions since they are relatively more affordable to find substitutes than middle income households [2].

Table 3. Optimized meta-regression model.

\begin{tabular}{|c|c|c|c|}
\hline Variable & Coefficient. & Robust Std. Err. & $\mathbf{P}>\mathbf{t}$ \\
\hline constant & $9.1820 * * *$ & 0.7540 & 0.000 \\
\hline stypedum & $-1.0339 * * *$ & 0.3093 & 0.001 \\
\hline drinking & $-0.5175^{* *}$ & 0.2255 & 0.025 \\
\hline han $\times$ improve & $0.8084 * * *$ & 0.2360 & 0.001 \\
\hline geum $\times$ improve & $0.6238^{* *}$ & 0.2859 & 0.033 \\
\hline nakdong×improve & $0.9643 * * *$ & 0.3260 & 0.005 \\
\hline good & reference & & \\
\hline normal & -0.0610 & 0.2769 & 0.826 \\
\hline bad & $0.8988^{* * *}$ & 0.2777 & 0.002 \\
\hline toobad & -0.5121 & 0.3688 & 0.17 \\
\hline$f t f$ & -0.4324 & 0.3077 & 0.165 \\
\hline$c v m$ & 0.4087 & 0.2827 & 0.154 \\
\hline $\operatorname{tax}$ & $-1.5709^{* * *}$ & 0.4634 & 0.001 \\
\hline truncdum & 0.1217 & 0.2067 & 0.558 \\
\hline lowinc & reference & & \\
\hline medinc & $1.2876^{* * *}$ & 0.3374 & 0.000 \\
\hline highinc & $0.9524 * * *$ & 0.3362 & 0.006 \\
\hline trend & $-0.1342 * * *$ & 0.0207 & 0.000 \\
\hline Mean VIF & & 4.11 & \\
\hline $\mathrm{R}^{2}$ & & 0.78 & \\
\hline Observation & & 72 & \\
\hline
\end{tabular}


No. of study 30

*** significant at $1 \%$;* significant at $5 \%$.

Turing to the variables of main interest, the coefficients on the han $\times$ improve, geum $\times$ improve, and nakdong $\times$ improve represent the impact of increase in WQ grade in each river on WTP values. These variables are all positive and highly significant, indicating WTP values increase as WQ grade increases. Note that the magnitude of nakdong $\times$ improve coefficient is relatively larger than that of han $\times$ improve and geum $\times$ improve. This is probably due to historical water pollution incidents in Nakdong River where phenol was leaked into the river twice by Doosan Electronics in 1991.

\subsection{Validity tests of meta-regression model}

Based on meta-regression results presented in Table 3 we calculated the predicted WTP values using the parameters only statistically significant and compared these predicted values were to the original values to evaluate the credibility of the meta-regression model. The mean values of the predicted WTP and original WTP are presented in the first row in Table 4. As shown, two values are quite similar and the mean percentage difference between two values is only 0.731 ( $2^{\text {nd }}$ row in Table 4$)$. This implies a relatively small error of our prediction. Furthermore, the insignificant t-statistics of the paired $t$-test in the third row in Table 4 indicates the meta-predicted values and original values are not statistically different. Similarly, the result of Pearson's correlation test indicated that there were positive and significant correlations between two values. Therefore, our meta-regression model is inclinable to predict high WTP values when original WTP values are higher and vice versa. 
Based on both paired $t$-test and correlation analysis, we are fairly confident that our meta-regression model is credible for benefit assessments.

Table 4. Result of statistical tests for the validation of meta-regression model.

\begin{tabular}{lcc}
\hline Category & Predicted WTP & Original WTP \\
\hline Mean & 8.16 & 8.10 \\
Percent difference of mean ${ }^{\text {a }}$ & 0.731 \\
Paired $t$-test $(\mathrm{N})$ & $-0.838(71)$ \\
Pearson's correlation coefficient & $0.804^{*}$ \\
\hline
\end{tabular}

${ }^{\text {a }}$ calculated as $[($ predicted WTP - original WTP $) /$ predicted WTP $] \times 100 ; * \gamma$ significant at $1 \%$ level.

5. Policy evaluation: benefit-cost analysis

Given the positive and significant coefficients associated with water quality improvement, it is straightforward to calculate the MWTP (benefits) for each river basin using Equation (2). Table 5 shows the result of benefits estimated from the use of water resource in each river basin.

As shown in Table 5, the mean and median MWTP are calculated to be different for each river because of different sample values and different magnitude of coefficients associated with water quality improvement. In other words, even though each river is the primary water resource that generates many beneficial services to its own stakeholders, the benefits provided by each river could be different depending on the water quality conditions in each river. For example, the mean and median WTP are calculated to be about KRW 4738 (about US \$4.7) and KRW 4433 (about US \$4.4) per household per month in Han River case, respectively, which is highest among three rivers. For the Geum River case, the mean and median WTP are extrapolated to be smaller than Nakdong River case, which is 
probably due to relatively small coefficients on geum $\times$ improve variable despite higher sample values in the dataset.

Table 5. Mean and Median MWTP associated with increase in WQ grade by each river.

\begin{tabular}{lcccc}
\hline River & Mean values $^{\text {a }}$ & Median values $^{\text {a }}$ & Mean MWTP & Median MWTP \\
\hline Han & $5,861.2$ & $5,484.1$ & $4,738.0$ & $4,433.2$ \\
Nakdong & $3,055.0$ & $3,133.0$ & $2,946.0$ & $3,021.2$ \\
Geum & $3,250.5$ & $3,046.4$ & $2,027.7$ & $1,900.4$ \\
\hline
\end{tabular}

* Values are in $2015 \mathrm{KRW} /$ household $/$ month; ${ }^{\text {a }}$ sample values in the dataset.

Given the median WTP in Table 5, we calculated the annual MWTP and total benefits for each river applying total number of households who paid water use charges in 2015 in each river basin. The results are presented in Table 6 . The total benefits provided by Han, Nakdong, and Geum River are estimated to be about KRW 490 billion, KRW 173 billion, and KRW 50 billion per year, respectively. The grand total of benefits provided by three rivers came to be about KRW 713 billion per year. We then compared these benefits to the RMFs (costs) that each river basin invested in the projects to manage water quality conditions such as environmental treatment infrastructure projects, water quality improvement projects, land purchase and riparian zone projects, and the total pollutant management projects in 2015. The comparison of benefits to costs shows that there are relatively large differences in terms of benefit-cost ratio between rivers (i.e., last column of table 6).

Table 6. Annual MWTP, benefit assessment, and benefit-cost ratios associated with water management in each river.

\begin{tabular}{|c|c|c|c|c|c|}
\hline River & Annual & No. of & Total Benefit (A) & Total Cost (B) & Benefit-Cost \\
\hline
\end{tabular}




\begin{tabular}{lccccc}
\hline & MWTP $^{\text {a }}$ & Household & (billion Won/year) & (billion Won/year) & Ratio (A/B) \\
\hline Han & $53,198.2$ & $9,210,710$ & 490.0 & 433.4 & 1.13 \\
Nakdong & $36,254.6$ & $4,773,567$ & 173.1 & 228.0 & 0.76 \\
Geum & $22,805.1$ & $2,193,688$ & 50.0 & 113.0 & 0.44 \\
Grand Total & - & - & 713.1 & 774.3 & 0.92 \\
\hline
\end{tabular}

* Annual MWTP, total benefit, and total cost are in $2015 \mathrm{KRW}$.

a Annual MWTP is based on Median MWTP in Table 5 since the null hypothesis of normality test for the mean values in the dataset is rejected.

For Han River case, the benefit-cost ratio indicates that benefits are enough to offset the costs spent in water quality improvement projects. Therefore, it seems that the Han River has been making an efficient investment since they are more than recovering their investments. In terms of Nakdong and Geum River case, however, the benefits are not large enough to offset the costs used in water management. Thus, in this empirical case one could judge that two rivers may not be making a reasonable investment, which raises issues associated with the operational inefficiencies of RMFs.

Based on the comparison of benefits and costs, we provide a few policy implications that can be useful to improve the efficiency of water resource management. Firstly, since the stakeholders belonging to each river gained different benefits, it would be reasonable to differentiate the amounts of water use charges in each river. Currently, the same amounts of water use charges in the three river basins are imposed on the water users. However, it would be more rational to levy more (less) costs on the water users who received more (less) benefits from the use of water resources [2]. Secondly, the RMFs should be operated more efficiently. Since the implementation of the RMFs, the majority of the funds have been invested in resident support projects and wastewater treatment infrastructure projects. 
However, overinvestment in these projects has raised on-going debates between stakeholders and the National Assembly Research Service pointed out the operational inefficiency of RMFs in 2012. Recently, the main sources of water pollution in the rivers are attributed from the non-point sources, particularly from the agriculture and livestock farming in the upstream of the river basin. Therefore, the RMFs should be invested in the water quality projects that can better leverage funds to reduce non-point source pollutions in the upstream of the river basin, which can result in improving overall water quality. For instance, if the priority of RMFs investment is given to the purchase of agricultural lands in the upstream areas, overall water quality objectives can be achieved at lower costs [24]. Thirdly, since water conditions in each river basin are unique, the operation of the RMFs should be tailored for each river. Each river basin has a different pollution source, which implies investment decisions of RMFs should be based on the natural properties of the river as well as the nature of the pollution affecting it in each river. Finally, a collaborative governance approach would be merit to consider for the effective water management. A collective management approach with stakeholder engagement in setting regulations at the local level can create buy-in, increase trust in government processes, and ultimately find effective solutions to achieve desired water quality outcomes. Stakeholder engagement through inclusive basin water governance is increasingly recognized as critical to secure support for reforms, raise awareness about water risks and costs, increase users' willingness to pay, and to handle conflicts [25]. 


\section{Conclusions}

Applying the logic of benefit transfer approaches, this study aimed to evaluate the economic efficiency of water resource management in South Korea based on benefit-cost comparison and to provide a valuable guideline that can help maintain the sustainability of water resources.

With the total of 72 observations from 30 studies obtained from the EVIS provided by KEI, we specified a meta-regression model which allows for estimating different benefits provided by each river. We tested the credibility of our meta-regression model. Based on statistical tests, we found that our model is suitable for benefit assessments. Using the coefficients associated with water quality improvement, we computed the marginal benefits (MWTP) for the each river basin. We then compared total benefits to the total costs which are used to manage water quality conditions in each river to assess how well water management is maintained in economic aspects.

Based on the benefit-cost analysis, this study recommended a few policy options including the equity of imposing water use charges, operational efficiency of RMFs, and stakeholder engagement for inclusive water governance that can be useful to maintain the sustainability of water resource management in the long-run.

To conclude, this study would be updated in the future to improve the reliability of meta-regression analysis when more databases associated with water resource management in Korea are constructed. Moreover, a further research which can address on-going debates between stakeholders regarding the suitability of amount of water use charges should be carried out. 
Acknowledgments: This study was funded by the research project (GP2018-11) of the Korea Environment Institute (KEI).

Author Contributions: Ahn conceived the study and supervised the process of manuscript development. Kim analyzed the data, performed econometric analysis, and wrote main text. Conflicts of Interest: The authors declare no conflict of interest. 


\section{Appendix A}

Table A1. The list of original studies used in meta-regression analysis.

\begin{tabular}{|c|c|c|c|c|c|c|c|}
\hline Id & Study Area & Year & $\begin{array}{l}\text { Valuation } \\
\text { Technique }\end{array}$ & WQ Improvement a & Baseline WQ Grade d & $\begin{array}{c}\text { Value } \\
\text { Measured }\end{array}$ & $\begin{array}{c}\text { No. of } \\
\text { WTP Estimates }\end{array}$ \\
\hline 1 & Han River & 1996 & CVM & 1 & G3 & Total Value & 1 \\
\hline 2 & Han River & 1993 & CVM & 1 & $\mathrm{n} / \mathrm{a}$ & Drinking & 4 \\
\hline 3 & Geum River & 2000 & CVM & 1 or 2 & G4 & Total Value & 4 \\
\hline 4 & Han River & 2000 & CVM & 2 & G3 & Total Value & 1 \\
\hline 5 & Han River & 2000 & CVM & 2 & G3 & Total Value & 3 \\
\hline 6 & Han River & 2000 & CVM & 2 & G3 & Total Value & 1 \\
\hline 7 & Han River & 2001 & CVM & 2 & G3 & Drinking & 1 \\
\hline 8 & Nakdong River & 2001 & CVM & 1 & G3 & Total Value & 1 \\
\hline 9 & Han River & 2001 & CVM & 2 & G3 & Recreation & 1 \\
\hline 10 & Han River & 2001 & CVM & 1 & G3 & Total Value & 1 \\
\hline 11 & Han River & 2003 & CVM & 1 & G2 & Recreation & 1 \\
\hline 12 & Han River & 2003 & CVM & 2 & G3 & Drinking & 4 \\
\hline 13 & Han River & 2003 & CVM & 2 & G3 & Recreation & 2 \\
\hline 14 & Nakdong River & 2004 & CVM & 2 & G3 & Drinking & 1 \\
\hline 15 & Nakdong River & 2004 & CVM & 2 & G3 & Total Value & 1 \\
\hline 16 & Han River & 2004 & $\mathrm{CE}$ & 1 & G3 or G2 & Total Value & 2 \\
\hline 17 & Nakdong River & 2006 & CVM & 2 & G3 & Total Value & 2 \\
\hline 18 & Han River & 2006 & CVM & 2 & G3 & Drinking & 2 \\
\hline 19 & Nakdong River & 2006 & CVM & 2 & G3 & Total Value & 2 \\
\hline 20 & Han River & 2007 & CVM & 1 & G3 & Total Value & 6 \\
\hline 21 & Han River & 2007 & $\mathrm{CE}$ & 1 or 2 & G5 or G4 or G3 or G2 & Total Value & 9 \\
\hline 22 & Han River & 2007 & CVM & 2 & $\mathrm{G} 3$ & Total Value & 1 \\
\hline 23 & Nakdong River & 2008 & CVM & 1 & G3 & Total Value & 4 \\
\hline 24 & Geum River & 2008 & CVM & 2 & G5 & Total Value & 1 \\
\hline 25 & Nakdong River & 2009 & CVM & 2 & G3 & Drinking & 8 \\
\hline 26 & Nakdong River & 2010 & CVM & 1 & G2 & Drinking & 1 \\
\hline 27 & Geum River & 2012 & CVM & 1 & $\mathrm{n} / \mathrm{a}$ & Recreation & 2 \\
\hline 28 & Han River & 2014 & $\mathrm{CE}$ & 1 & $\mathrm{n} / \mathrm{a}$ & Recreation & 2 \\
\hline 29 & Geum River & 2015 & $\mathrm{CE}$ & 1 & $\mathrm{n} / \mathrm{a}$ & Recreation & 2 \\
\hline 30 & Geum River & 2015 & $\mathrm{CE}$ & 1 & $\mathrm{n} / \mathrm{a}$ & Recreation & 1 \\
\hline
\end{tabular}

\footnotetext{
${ }^{\mathrm{a}}$ level of WQ improvement calculated by hypothetical WQ grade minus baseline WQ grade; ${ }^{\mathrm{b}}$ baseline WQ grade, n/a: not available.
} 
References

1. Phaneuf, D. J., V. K. Smith, R. B. Palmquist, and J. C. Pope. Integrating Property Value and Local Recreation Models to Value Ecosystem Services in Urban Watersheds. Land Economics 2008, 84 (3): 361-381.

2. Shin, H.J.; Kim, H.N.; Jeon, C.H.; Jo, M.H.; Nguyen, T.T.; Tenhunen, J. Benef it transfer for water management along the Han River in South Korea using M eta-Regression Analysis. Water 2016, 8, 492.

3. Champ, P.A., Boyle, K.J., and Brown, T.C. A Primer on Nonmarket Valuation. Second Edition, Springer, 2017.

4. Columbo, S.; Hanley, N. How can we reduce the errors from benefits transfer? An investigation using the choice experiment method. Land Econ. 2008, 84, 1 28-147.

5. Griffiths, C.; Wheeler, W. Benefit-cost analysis of regulations affecting surface water quality in the United States. In Cost-Benefit Analysis and Water Resour ces Management; Edward Elgar: Cheltenham, UK, 2005.

6. Iovanna, R.; Griffiths, C. Clean water, ecological benefits, and benefits transfer: A work in progress at the U.S. EPA. Ecol. Econ. 2006, 60, 473-482.

7. McComb, G.; Lantz, V.; Nash, K.; Rittmaster, R. International valuation databa ses: Overview, methods and operational issues. Ecol. Econ. 2006, 60, 461-472.

8. Muthke, T.; Holm-Mueller, K. National and international benefit transfer testing with a rigorous test procedure. Environ. Resour. Econ. 2004, 29, 323-336.

9. Rosenberger, R.S.; Loomis, J.B. Benefit Transfer of Outdoor Recreation Use V alues: A Technical Document Supporting the Forest Service Strategic Plan (200 0 Revisions); No. RMRS-GTR-72; U.S. Department of Agriculture, Forest Servi 
ce: Washington, DC, USA, 2001.

10. Shrestha, R.; Loomis, J. Testing a meta-analysis model for benefit transfer in in ternational outdoor recreation. Ecol. Econ. 2001, 39, 67-83.

11. Kim, H.N. The Demonstration and Capture of an Ecosystem Service Value: Th ree Different Methodological Approaches. Ph.D. Thesis, University of Alberta, Edmonton, AB, Canada, January 2015.

12. Kim, H.N.; Boxall, P.C.; Adamowicz, W.L. The demonstration and capture of $\mathrm{t}$ he value of an ecosystem service: A quasi-experimental hedonic property analys is. Am. J. Agric. Econ. 2016, 98, 819-837.

13. Kim, H.N.; Boxall, P.C.; Adamowicz, W.L. Analysis of the impact of water qu ality changes on residential property prices. Water Resources and Economics. 2 $016,16,1-14$.

14. Boutwell, J.L.; Westra, J.V. Benefit transfer: A review of methodologies and ch allenges. Resources 2013, 2, 517-527.

15. Desvousges, W.H.; Johnson, F.R.; Banzhaf, H.S. Environmental Policy Analysis with Limited Information: Principles and Application of the Transfer Method; Edward Elgar: Cheltenham, UK, 1998

16. Johnston, R.J.; Rolfe, J.; Rosenberger, R.S.; Brouwer, R. Benefit Transfer of En vironmental and Resource Values: A Guide for Researchers and Practitioners; S pringer: Dordrecht, The Netherlands, 2015.

17. Smith, V.K.; van Houtven, G.; Pattanayak, S.K. Benefit transfer via preference calibration: Prudential algebra for policy. Land Econ. 2002, 78, 132-15

18. Hanley, N.; Wright, R.E.; Alvarez-Farizo, B. Estimating the economic value of improvements in river ecology using choice experiments: An application to the water framework directive. J. Environ. Manag. 2006, 78, 183-193. 
19. Hanley, N.; Colombo, S.; Tinch, D.; Black, A; Aftab, A. Estimating the benefit s of water quality improvements under the water framework directive: Are bene fits transferable? Eur. Rev. Agric. Econ. 2006, 33, 391-413.

20. Bateman, I.J.; Brainard, J.S.; Lovett, A.A. Modeling Woodland Recreation Dem and Using Geographical Information Systems: A Benefit Transfer Study; Global Environmental Change Working Paper 95-06; Center for Social and Economic Research on the Global Environment (CSERGE); University College London an d University of East Anglia: Norwich, UK, 1995.

21. Brisson, I.; Pearce, D. Benefit Transfer for Disamenity from Waste Disposal; G lobal Environmental Change Working Paper WM 95-06; Center for Social and Economic Research on the Global Environment (CSERGE); University College London and University of East Anglia: Norwich, UK, 1995.

22. Brouwer, R. Environmental value transfers: State of the art and future prospects . Ecol. Econ. 2000, 32, 137-152.

23. Ruijrok, E. Transferring economic values on the basis of an ecological classific ation of nature. Ecol. Econ. 2001, 39, 399-408.

24. Choi, I.C.; Kim, H.N.; Shin, H.J.; Tenhunen, J.; Nguyen, T.T. Willingness to P ay for a Highland Agricultural Restriction Policy to Improve Water Quality in South Korea: Correcting Anomalous Preference in Contingent Valuation Metho d. Water 2016, 8, 547.

25. OECD (2015), Stakeholder Engagement for Inclusive Water Governance, OECD Studies on Water, OECD Publishing, Paris. http://dx.doi.org/10.1787/9789264231122-en 